Original

\title{
Promoting Effect of Sodium L-Ascorbate on N-Butyl-N-(4-hydroxybutyl)nitrosamine-induced Renal Pelvic Carcinogenesis in SD/cShi Rats of Both Sexes
}

\author{
Takashi Murai ${ }^{1,2}$, Akihiro Koide $^{3}$, Hideyuki Miyauchi², Satoshi Inoue ${ }^{2}$, \\ Toshiyuki Maruyama ${ }^{2}$, Susumu Makino ${ }^{4}$, Satoru Mori ${ }^{1}$, Hideki Wanibuchi ${ }^{1}$, \\ Yukio Mori ${ }^{3}$, and Shoji Fukushima ${ }^{1}$ \\ ${ }^{1}$ First Department of Pathology, Osaka City University Medical School, 1-4-3 Asahi-machi, Abeno-ku, Osaka \\ 545-8585, Japan \\ 2 Developmental Research Laboratories, Shionogi \& Co., Ltd., 3-1-1 Futaba-cho, Toyonaka, Osaka 561-0825, Japan \\ ${ }^{3}$ Laboratory of Radiochemistry, Gifu Pharmaceutical University, 6-1 Mitahora-higashi 5-chome, Gifu 502-8585, Japan \\ ${ }^{4}$ Aburahi Laboratories Shionogi Research Laboratories Shionogi \& Co., Ltd., 1405 Koka-cho, Koka-gun, Shiga \\ 520-3423, Japan
}

\begin{abstract}
Susceptibility to the promoting effects of sodium L-ascorbate (Na-AsA) on the development of pelvis and urinary bladder tumors in male and female $\mathrm{SD} / \mathrm{cShi}$ rats, featuring spontaneous hydronephrosis, was investigated. Rats received $0.05 \% \mathrm{~N}$-butyl- $N$-(4-hydroxybutyl)nitrosamine (BBN) in their drinking water for 4 weeks and subsequently given basal diet with or without a 5\% Na-AsA supplement for 32 weeks. Histopathological examination revealed the promoting effect of Na-AsA on not only the development of urinary bladder tumors but also renal pelvic tumors in the animals of both sexes in this two-stage carcinogenesis experiment, the effect being more prominent in males. Administration of either BBN or Na-AsA alone also induced papillomas and papillary or nodular hyperplasia of renal pelvis or urinary bladder, respectively, in male but not female rats. However, the 5-bromo-2'-deoxyuridine-labeling index of urothelium in the pelvis and bladder increased slightly in male rats and significantly in female rats given NaAsA alone for 8 weeks. $N$-butyl- $N$-(3-carboxypropyl)nitrosamine, which is a metabolite of BBN and proximate carcinogen, was found more in the urine of urinary bladder than that of renal pelvis. These results indicate that the urothelium of the renal pelvis and urinary bladder in $\mathrm{SD} / \mathrm{cShi}$ rats is susceptible to promoting effects of Na-AsA in the present two stage model urinary tract carcinogenesis, with the urinary bladder of male rats as the most sensitive organ. (J Toxicol Pathol 2003; 16: 231-236)
\end{abstract}

Key words: $\mathrm{SD} / \mathrm{cShi}$ rat, renal pelvic carcinogenesis, urinary bladder carcinogenesis, promotion, sodium L-ascorbate, $\mathrm{N}$-butyl- $N$-(4-hydroxybutyl)nitrosamine

\section{Introduction}

Experimental carcinogenesis in the urinary bladder can be divided into at least two stages, initiation and promotion and a number of environmental agents that lack genotoxicity have been reported to act as promoters ${ }^{1}$. Some of these agents, including various sodium salts of organic acids, like sodium L-ascorbate (Na-AsA) and sodium saccharin, have the potential to increase the proliferation of epithelial cells in the second stage of rat urinary bladder carcinogenesis ${ }^{1}$.

Although a great number of studies of promoting

Received: 22 July 2003, Accepted: 12 September 2003

Mailing address: Takashi Murai, Developmental Research

Laboratories Shionogi \& Co., Ltd., 3-1-1 Futaba-cho, Toyonaka,

Osaka 561-0825, Japan

TEL: 81-6-6331-8261 FAX: 81-6-6332-6385

E-mail: takashi.murai@shionogi.co.jp mechanisms of sodium salts have been carried out focusing on the urinary bladder, only limited information is available with regard to the situation in the urothelium of the renal pelvis. This is partly because an appropriate animal model of renal pelvic carcinogenesis has hitherto been lacking. However, various causative agents for renal pelvic tumors have been reported to exist $\mathrm{t}^{-4}$ and studies of promoting potential in the renal pelvis using appropriate experimental animals is important for prediction of human risk.

$\mathrm{SD} / \mathrm{cShi}$ rats, which have been established by fullsibling mating of SD rats supplied in 1961 to Aburahi Lab., Shionogi \& Co., Ltd. (Koka, Shiga), from Charles River Breeding Laboratory in the United States, have bilateral hydronephrosis that is recessively inherited ${ }^{5}$. We previously reported that treatment with a urinary bladder carcinogen, $N$ butyl- $N$-(4-hydroxybutyl)nitrosamine (BBN), is able to induce primary renal pelvic carcinomas in $\mathrm{SD} / \mathrm{cShi}$ rats with 
a clear positive correlation being found between renal pelvic carcinogenesis and hydronephrosis ${ }^{6,7}$.

In the present study, promoting activity of Na-AsA in the renal pelvis and urinary bladder was compared using $\mathrm{SD} /$ cShi strain of rats.

\section{Materials and Methods}

\section{Animals}

The animals used in the present study were reared in accordance with recommendations of the Guide for the Care and Use of Animals ${ }^{8}$ and all procedures were approved by Shionogi Animal Care and Use Committee. Five-week-old male SD/cShi rats were raised in Aburahi Lab. The animals were housed 2 rats per cage (RT type, Charles River Japan, Inc.) in a room maintained under a 12-h (7:00-19:00) lightdark cycle, at a constant temperature of $25 \pm 1^{\circ} \mathrm{C}$ and relative humidity of $55 \pm 10 \%$. All rats were given MF diet (Oriental Yeast Co., Tokyo) and water ad libitum throughout the experiment. Mortality and general condition were checked daily.

\section{Chemicals}

The carcinogen, BBN was obtained from Tokyo Kasei Kogyo Co., Ltd., Tokyo. Na-AsA (food additive grade, 99.8\% pure) was from Takeda Chemical Industries, Ltd., Osaka. The MF diet containing Na-AsA was prepared by Oriental Yeast Co., Tokyo. 5-Bromo-2'-deoxyuridine (BrdU) was purchased from Sigma, St. Louis, MO, U.S.A. while $N$-butyl- $N$-(3-carboxypropyl)nitrosamine (BCPN) was synthesized in our laboratory according to the method of Okada et al. ${ }^{9}$. The purity of BCPN was confirmed to be $>99 \%$ by high-performance liquid chromatography (HPLC).

\section{Induction of urinary tract tumors; Experiment 1}

Twenty-five male and thirty female rats (6-week-old) were randomly divided into groups as shown in Table 1. In the first 4 weeks of the experiment, the rats in groups 1 (12 rats), 2 (9 rats), 4 (12 rats), and 5 (12 rats) were given drinking water containing $0.05 \% \mathrm{BBN}$ by volume while those of groups 3 (4 rats) and 6 (6 rats) were maintained without carcinogen exposure. During experimental weeks 5-36, groups 1, 3, 4, and 6 were fed powdered MF diet containing $5 \% \mathrm{Na}$-AsA and groups 2 and 5 were fed pelleted MF diet. Body weights were measured weekly up to week 4 and thereafter every 4 weeks. The amounts of water containing BBN (experimental weeks 0-4) and food (experimental weeks 5-36) consumed were measured during two consecutive days on a per-cage basis. The intake of sodium and total ascorbic acid (TAA) was calculated in consideration of the preexistent amount of sodium and ascorbic acid in food. At the end of the experiment, all survivors were killed for pathological examination.

\section{DNA synthesis examination; Experiment 2}

Rats of both sexes (6-week-old) was randomly divided into 4 groups as shown in Table 5. The animals were fed powdered MF diet containing 5\% Na-AsA (groups 1 and 3) or pelleted MF diet (groups 2 and 4, 6 rats each) for 8 weeks. The amounts of food consumed were measured over two consecutive days on a per-cage basis at experimental weeks 4 and 8 . At the end of the experiment, $\operatorname{BrdU}(50 \mathrm{mg} / \mathrm{kg})$ dissolved in saline was administered intraperitoneally to all rats 1 hour before ether anesthetization and autopsy. In order to avoid any variance between groups by circadian rhythms demonstrated in a number of cell cycle components, the animals were sequentially killed so that one rat from each of the groups was simultaneously killed under ether anesthesia.

\section{$B C P N$ detection in urine from the renal pelvis and urinary bladder; Experiment 3}

Four male SD/cShi rats (9-week-old) were administered orally with $20 \mathrm{ml}$ per $\mathrm{kg}$ body weight of $0.05 \% \mathrm{BBN}(10 \mathrm{mg} / \mathrm{kg}$ bw as BBN). Four hours after administration, urine samples were collected from the renal pelvis and urinary bladder of rats anesthetized with pentobarbital. Treatment of the urine samples, and extraction, separation, and determination of BCPN by thinlayer chromatography and HPLC were performed as described in detail previously ${ }^{10}$.

\section{Urinalysis}

Fresh urine samples obtained by forced urination in the morning (9:00-11:00 a.m.) were used for measurement of $\mathrm{pH}$, TAA and sodium ion concentration and the examination of occult blood. Urinalysis was performed at experimental weeks 12, 24, and 35 in Experiment 1 and at experimental weeks 4 and 8 in Experiment 2. The examination of $\mathrm{pH}, \mathrm{L}-$ ascorbic acid concentration, and occult blood was accomplished with urinary test papers (Merck \& Co., Inc., and Hoechst Roussel Pharm, Inc., Germany). The sodium ion concentration was estimated by atomic absorbance chemical analysis (AA-175 atomic absorption spectrophotometer; Varian Techtron Co., Canberra, Australia).

\section{Pathological examination}

In Experiment 1, rats were killed under ether anesthesia and the urinary bladders were inflated and fixed with $10 \%$ phosphate-buffered formalin ( $\mathrm{pH} 7.4)$. After fixation, they were weighed, cut into 8 to 12 pieces, and routinely embedded in paraffin. The kidneys were also weighed. The whole ureters were cut to about $3 \mathrm{~mm}$ in length. Sections were stained with hematoxylin and eosin (H\&E) for light microscopic examination. Histopathological lesions of urinary tract epithelium were classified into 4 categories: simple hyperplasia, papillary or nodular (PN) hyperplasia, papilloma, and carcinoma, as described previously ${ }^{11}$.

In Experiment 2 immunohistochemical BrdU staining was performed to assess DNA synthesis ${ }^{11}$. After the urinary bladders were processed as described in Experiment 1, the sections were incubated with a primary monoclonal antibody $(1: 2000)$ against $\mathrm{BrdU}(\mathrm{DAKO})$ at $4{ }^{\circ} \mathrm{C}$ overnight. The avidin-biotin-peroxidase complex (ABC) method using 
Vectastain ABC Kit (Vector Laboratories Inc., Burlingame, CA, U.S.A.) was used according to the manufacturer's protocol, with diaminobenzidine (DAKO) as the chromogen. The labeling index (\%) was microscopically defined as the numbers of cells positively stained with anti-BrdU antibody per the total number of epithelial cells counted (1000 cells per slide).

\section{Data evaluation}

Statistical analysis of the incidence of histopathological lesions was performed with the Fisher's exact probability test. The other data were evaluated by Student's $t$-test.

\section{Results}

\section{Experiment 1}

General conditions: Data for survival, body weights, organ weights, and intakes of BBN, sodium and TAA are summarized in Table 1. One rat each in groups 2 and 4 died due to pyelonephritis and nephroblastoma at experimental weeks 20 and 24, respectively. The relative kidney weights differed significantly between groups 4 and 5. The relative weights of urinary bladders of rats given both $\mathrm{BBN}$ and $\mathrm{Na}-$ AsA were higher than the $\mathrm{BBN}$ or $\mathrm{Na}-\mathrm{As} \mathrm{A}$ alone group values (group 1 versus groups 2 or 3 ; group 4 versus groups 5 or 6 ), but significant difference was not seen in between groups 1 and 2 or 3 and groups 4 and 6 due to larger standard deviation.

The amount of BBN intake did not vary with the group in either sex. The intakes of sodium and TAA were not different between groups 1 and 3 or between groups 4 and 6 .

The results of urinalysis are summarized in Table 2 . The urinary $\mathrm{pH}$ and the urinary concentrations of sodium ion and ascorbic acid were increased significantly by the administration of $\mathrm{Na}$-AsA but they were not significantly different between groups 1 and 3 or groups 4 and 6 . Occult blood was observed at all time points in groups 1 and 2 and at experimental weeks 24 and 35 in group 4, but not in group 5 . Increase in incidences with time was observed in females of group 4 but not males. In groups 3, 5, and 6 occult blood was observed sporadically at only one of 3 points examined.

Incidences of urinary tract tumors: Data for histopathological lesions in the kidney are summarized in Table 3. The incidence of renal pelvic carcinomas and/or papillomas was higher in the rats given both BBN and NaAsA (groups 1 and 4) than with BBN alone (groups 2 and 5), although there was no statistical significance. The incidence of PN hyperplasia observed in the rats given both $\mathrm{BBN}$ and Na-AsA (groups 1 and 4) was significantly higher than the $\mathrm{BBN}$ alone groups 2 and 5. In female rats given both $\mathrm{BBN}$ and $\mathrm{Na}-\mathrm{AsA}$, the incidence of simple hyperplasia was significantly higher than with BBN alone. Hydronephroses

Table 1. Data for Survival, Average Body and Organ Weights and Intakes of BBN (wks 1-4), Sodium (wks 5-36), and Ascorbic Acid (wks 536) in Experiment 1

\begin{tabular}{|c|c|c|c|c|c|c|c|c|c|c|c|}
\hline \multirow[t]{2}{*}{ Group } & \multirow[t]{2}{*}{ Sex } & \multicolumn{2}{|c|}{ Treatment } & \multirow{2}{*}{$\frac{\text { Survivors }^{\mathrm{a}}}{\mathrm{A}}$} & \multicolumn{2}{|c|}{ Body weight $(\mathrm{g})^{\mathrm{b}}$} & \multirow{2}{*}{$\begin{array}{l}\text { Relative kidney } \\
\text { weight } \\
(\mathrm{mg} / 100 \mathrm{~g} \mathrm{bw})^{\mathrm{b}}\end{array}$} & \multirow{2}{*}{$\begin{array}{l}\text { Relative urinary } \\
\text { bladder weight } \\
(\mathrm{mg} / 100 \mathrm{~g} \mathrm{bw})^{b}\end{array}$} & \multirow{2}{*}{$\begin{array}{c}\text { BBN } \\
\text { intake } \\
(\mathrm{mg} / \mathrm{kg} / \mathrm{day})^{\mathrm{b}}\end{array}$} & \multirow{2}{*}{$\begin{array}{c}\text { Sodium } \\
\text { intake } \\
(\mathrm{mg} / \mathrm{kg} / \text { day })^{\mathrm{b}}\end{array}$} & \multirow{2}{*}{$\begin{array}{c}\text { Total ascorbic } \\
\text { acid intake } \\
(\mathrm{mg} / \mathrm{kg} / \text { day })^{\mathrm{b}}\end{array}$} \\
\hline & & $\mathrm{BBN}$ & $\mathrm{Na}-\mathrm{As}$ & & Initial & Final & & & & & \\
\hline 1 & male & + & + & $12 / 12$ & $192 \pm 14$ & $565 \pm 28^{\mathrm{c}}$ & $609 \pm 229$ & $96 \pm 81$ & $62 \pm 9$ & $377 \pm 80^{\mathrm{c}}$ & $2004 \pm 427^{\mathrm{c}}$ \\
\hline 2 & male & + & - & $8 / 9$ & $200 \pm 23$ & $634 \pm 29$ & $506 \pm 29$ & $42 \pm 5$ & $60 \pm 11$ & $90 \pm 8$ & $1 \pm 0$ \\
\hline 3 & male & - & + & $4 / 4$ & $219 \pm 18$ & $577 \pm 26^{\mathrm{c}}$ & $602 \pm 48^{c}$ & $51 \pm 8^{c}$ & & $362 \pm 15^{\mathrm{c}}$ & $1922 \pm 81^{c}$ \\
\hline 4 & female & e + & + & $11 / 12$ & $142 \pm 5$ & $319 \pm 20^{\mathrm{d}, \mathrm{e}}$ & $735 \pm 199^{d}$ & $56 \pm 26^{d}$ & $79 \pm 7$ & $444 \pm 106^{\mathrm{d}}$ & $2358 \pm 562^{d}$ \\
\hline 5 & female & $e+$ & - & $12 / 12$ & $141 \pm 12$ & $368 \pm 22$ & $579 \pm 62$ & $39 \pm 5$ & $76 \pm 13$ & $105 \pm 18$ & $1 \pm 0$ \\
\hline 6 & female & $e-$ & + & $6 / 6$ & $146 \pm 4$ & $342 \pm 19^{d}$ & $644 \pm 79$ & $45 \pm 5^{d}$ & & $447 \pm 38^{\mathrm{d}}$ & $2377 \pm 203^{d}$ \\
\hline
\end{tabular}

a: Survivors: No. alive at the end / No. at the start of experiment. b: Mean \pm SD. c: Significantly different from group 2 at $\mathrm{P}<0.05$ (Student's $t$-test). d: Significantly different from group 5 at $\mathrm{P}<0.05$ (Student's $t$-test). e: Significantly different from group 6 at $\mathrm{P}<0.05$ (Student's $t$-test).

Table 2. Urinalysis Data for Two-Stage Carcinogenesis in Experiment 1

\begin{tabular}{|c|c|c|c|c|c|c|c|c|c|c|}
\hline \multirow[t]{3}{*}{ Group } & \multirow[t]{3}{*}{ Sex } & \multicolumn{2}{|c|}{ Treatment } & \multirow{3}{*}{ Number of rats examined } & \multirow[t]{3}{*}{$\mathrm{pH}^{\mathrm{a}, \mathrm{b}}$} & \multirow{3}{*}{$\begin{array}{l}\text { Sodium ion }{ }^{\mathrm{a}, \mathrm{b}} \\
(\mathrm{mmol} / \mathrm{L})\end{array}$} & \multirow{3}{*}{$\begin{array}{l}\text { Ascorbic acid }{ }^{a, b} \\
(\mathrm{mg} / \mathrm{dL})\end{array}$} & \multirow{2}{*}{\multicolumn{3}{|c|}{$\frac{\text { Incidence of occult blood (\%) }}{\text { Experimental weeks examined at: }}$}} \\
\hline & & \multirow[t]{2}{*}{$\mathrm{BBN}$} & \multirow[t]{2}{*}{$\mathrm{Na}-\mathrm{AsA}$} & & & & & & & \\
\hline & & & & & & & & 12 & 24 & 35 \\
\hline 1 & male & + & + & 12 & $8.5 \pm 0.0^{\mathrm{c}}$ & $177.1 \pm 34.6^{\mathrm{c}}$ & $1230.6 \pm 389.4^{\mathrm{c}}$ & 25 & 33 & 33 \\
\hline 2 & male & + & - & 8 & $7.9 \pm 0.2$ & $72.5 \pm 24.2$ & $248.2 \pm 60.4$ & 75 & 38 & 50 \\
\hline 3 & male & - & + & 4 & $8.5 \pm 0.1^{\mathrm{c}}$ & $182.4 \pm 32.7^{\mathrm{c}}$ & $1100.0 \pm 508.5^{\mathrm{c}}$ & 0 & 0 & 25 \\
\hline 4 & female & + & + & 11 & $8.3 \pm 0.2^{\mathrm{d}}$ & $141.0 \pm 42.1^{\mathrm{d}}$ & $494.4 \pm 286.3^{d}$ & 0 & 18 & $36^{\mathrm{e}}$ \\
\hline 5 & female & + & - & 12 & $7.6 \pm 0.3$ & $40.7 \pm 22.5$ & $187.5 \pm 42.2$ & 25 & 0 & 0 \\
\hline 6 & female & - & + & 6 & $8.3 \pm 0.1^{\mathrm{d}}$ & $116.1 \pm 19.0^{\mathrm{d}}$ & $738.9 \pm 230.4^{\mathrm{d}}$ & 0 & 17 & 0 \\
\hline
\end{tabular}

a: Average data of experimental week 12, 24 and 35. b: Mean \pm SD. c: Significantly different from group 2 at $P<0.05$ (Student's $t$-test).

$\mathrm{d}$ : Significantly different from group 5 at $\mathrm{P}<0.05$ (Student's $t$-test). e: Significantly different from group 5 at $\mathrm{P}<0.05$ (Fisher's exact probably test). 
Table 3. Data for Kidney Lesions in Two-stage Carcinogenesis in Experiment 1

\begin{tabular}{|c|c|c|c|c|c|c|c|c|c|c|c|c|}
\hline \multirow[t]{3}{*}{ Group } & \multirow{3}{*}{ Sex } & \multirow{3}{*}{\multicolumn{2}{|c|}{$\frac{\text { Treatment }}{\text { BBN Na-AsA }}$}} & \multirow{3}{*}{$\begin{array}{c}\text { Number of } \\
\text { rats examined }\end{array}$} & \multicolumn{6}{|c|}{ No. of rats with renal pelvic lesions } & \multicolumn{2}{|c|}{ Other lesions } \\
\hline & & & & & \multirow{2}{*}{$\frac{\text { Simple hyperplasia }}{(\%)}$} & \multicolumn{2}{|c|}{ PN hyperplasia $\mathrm{P}$} & Papilloma & \multicolumn{2}{|c|}{ Carcinoma } & \multirow{2}{*}{$\frac{\text { Nephroblastoma }}{(\%)}$} & \multirow{2}{*}{$\frac{\text { hydronephrosis }}{(\%)}$} \\
\hline & & & & & & $(\%)$ & $(\%)$ & No. $/ \mathrm{rat}^{\mathrm{a}}$ & $(\%)$ & No./rat ${ }^{\mathrm{a}}$ & & \\
\hline 1 & male & + & + & 12 & $12(100)$ & $12(100)^{b}$ & $4(33)$ & $0.4 \pm 0.5$ & $3(25)$ & $0.4 \pm 0.7$ & 0 & $11(92)$ \\
\hline 2 & male & + & - & 8 & $8(100)$ & $1(13)$ & 0 & 0 & 0 & 0 & 0 & $8(100)$ \\
\hline 3 & male & - & + & 4 & $4(100)$ & $4(100)^{c}$ & $1(25)$ & $0.3 \pm 0.5$ & 0 & 0 & 0 & $4(100)$ \\
\hline 4 & femal & le + & + & 11 & $10(91)^{\mathrm{d}}$ & $5(45)^{\mathrm{e}}$ & $1(9)$ & $0.2 \pm 0.6$ & 0 & 0 & $2(18)$ & $11(100)$ \\
\hline 5 & femal & le + & - & 12 & $1(8)$ & $1(8)$ & 0 & 0 & 0 & 0 & 0 & $12(100)$ \\
\hline 6 & femal & le - & + & 6 & $4(67)^{\mathrm{e}}$ & 0 & 0 & 0 & 0 & 0 & 0 & $6(100)$ \\
\hline
\end{tabular}

a: Mean \pm SD. b: Significantly different from group 2 at $\mathrm{P}<0.01$ (Fisher's exact probability test). c: Significantly different from group 2 at $\mathrm{P}<0.05$ (Fisher's exact probability test). d: Significantly different from group 5 at $\mathrm{P}<0.01$ (Fisher's exact probability test). e: Significantly different from group 5 at $\mathrm{P}<0.05$ (Fisher's exact probability test).

Table 4. Data for Urinary Bladder Lesions in Two-stage Carcinogenesis in Experiment 1

\begin{tabular}{|c|c|c|c|c|c|c|c|c|c|c|}
\hline \multirow[t]{3}{*}{ Group } & \multirow[t]{3}{*}{ Sex } & \multicolumn{2}{|c|}{ Treatment } & \multirow{3}{*}{$\begin{array}{l}\text { Number of } \\
\text { rats examined }\end{array}$} & \multicolumn{6}{|c|}{ No. of rats with urinary bladder lesions } \\
\hline & & \multirow[t]{2}{*}{$\mathrm{BBN}$} & \multirow[t]{2}{*}{$\mathrm{Na}-\mathrm{AsA}$} & & \multirow{2}{*}{$\frac{\text { Simple hyperplasia }}{(\%)}$} & \multirow{2}{*}{$\frac{\text { PN hyperplasia }}{(\%)}$} & \multicolumn{2}{|c|}{ Papilloma } & \multicolumn{2}{|c|}{ Carcinoma } \\
\hline & & & & & & & $(\%)$ & No./rat ${ }^{\mathrm{a}}$ & $(\%)$ & No./rat ${ }^{\mathrm{a}}$ \\
\hline 1 & male & + & + & 12 & $12(100)^{b, c}$ & $9(75)^{\mathrm{c}}$ & $8(67)$ & $1.8 \pm 2.3^{\mathrm{d}}$ & $7(58)^{b}$ & $1.3 \pm 1.6^{\mathrm{d}}$ \\
\hline 2 & male & + & - & 8 & $3(38)$ & $2(25)$ & $2(25)$ & $0.5 \pm 0.8$ & 0 & 0 \\
\hline 3 & male & - & + & 4 & $1(25)$ & 0 & 0 & 0 & 0 & 0 \\
\hline 4 & female & + & + & 11 & $11(100)^{\mathrm{e}, \mathrm{f}}$ & $4(36)^{\mathrm{e}}$ & $3(27)$ & $0.7 \pm 2.1$ & $1(9)$ & $0.5 \pm 1.8$ \\
\hline 5 & female & + & - & 12 & $3(25)$ & 0 & 0 & 0 & 0 & 0 \\
\hline 6 & female & - & + & 6 & 00 & 0 & 0 & 0 & 0 & 0 \\
\hline
\end{tabular}

a: Mean \pm SD. b: Significantly different from group 2 at $\mathrm{P}<0.01$ (Fisher's exact probability test). c: Significantly different from group 3 at $\mathrm{P}<0.05$ (Fisher's exact probability test). d: Significantly different from group 2 at $\mathrm{P}<0.05$ (Student's $t$-test). e: Significantly different from group 5 at $\mathrm{P}<0.05$ (Fisher's exact probability test). f: Significantly different from group 6 at $\mathrm{P}<0.001$ (Fisher's exact probability test).

Table 5. Data for Average Body Weights, Intakes of Sodium and Total Ascorbic Acid, Urinary Analysis and BrdU Labeling Index (wks 0-8) in Experiment 2

\begin{tabular}{|c|c|c|c|c|c|c|c|c|c|c|c|c|}
\hline \multirow[t]{2}{*}{ Group } & \multirow{2}{*}{\multicolumn{2}{|c|}{ Sex Na-AsA }} & \multirow{2}{*}{$\begin{array}{l}\text { No. of rats } \\
\text { examined }\end{array}$} & \multicolumn{2}{|c|}{ s Body weight $(\mathrm{g})^{\mathrm{a}}$} & \multicolumn{2}{|c|}{ Intake $^{\mathrm{a}, \mathrm{b}}$} & \multicolumn{3}{|c|}{ Urinary analysis $^{\mathrm{a}, \mathrm{b}}$} & \multicolumn{2}{|c|}{ BrdU labeling index $(\%)^{2}$} \\
\hline & & & & Initial & Final & $\begin{array}{l}\text { Sodium } \\
\mathrm{mg} / \mathrm{kg} / \text { day) a }\end{array}$ & $\begin{array}{l}\text { Total ascorbic } \\
\text { acid }(\mathrm{mg} / \mathrm{kg} / \mathrm{da}\end{array}$ & y) & $\begin{array}{l}\text { Sodium ion } \\
(\mathrm{mmol} / \mathrm{L})\end{array}$ & $\begin{array}{c}\text { ascorbic acid } \\
(\mathrm{mg} / \mathrm{dL})^{\mathrm{b}}\end{array}$ & $\begin{array}{l}\text { Renal } \\
\text { pelvis }\end{array}$ & $\begin{array}{l}\text { Urinary } \\
\text { bladder }\end{array}$ \\
\hline 1 & male & + & 6 & $174 \pm 18$ & $478 \pm 30$ & $574 \pm 14$ & c $3053 \pm 77^{\mathrm{c}}$ & $8.5 \pm 0.1^{\mathrm{c}}$ & $175.3 \pm 37.4^{\mathrm{c}}$ & $1150.0 \pm 552.3^{\mathrm{c}}$ & $1.17 \pm 1.11$ & $0.75 \pm 0.88$ \\
\hline 2 & male & - & 6 & $171 \pm 19$ & $453 \pm 25$ & $154 \pm 8$ & $2 \pm 0$ & $8.0 \pm 0.2$ & $52.4 \pm 21.5$ & $225.0 \pm 68.9$ & $0.58 \pm 0.36$ & $0.10 \pm 0.06$ \\
\hline 3 & female & + & 6 & $140 \pm 15$ & $237 \pm 11^{\mathrm{c}}$ & c $\quad 539 \pm 67$ & c $2906 \pm 362^{c}$ & $8.4 \pm 0.1^{\mathrm{c}}$ & $198.4 \pm 37.9^{c}$ & $425.0 \pm 144.0^{\mathrm{c}}$ & $1.26 \pm 0.83^{\mathrm{c}}$ & $0.17 \pm 0.05^{\mathrm{c}}$ \\
\hline 4 & female & - & 6 & $154 \pm 23$ & $284 \pm 35$ & $158 \pm 25$ & $1 \pm 0$ & $7.8 \pm 0.2$ & $90.3 \pm 26.0$ & $125.0 \pm 27.4$ & $0.31 \pm 0.33$ & $0.07 \pm 0.08$ \\
\hline
\end{tabular}

a: Mean \pm SD. b: Average data of experimental week 4 and 8. c: Significantly different from each matched control at $\mathrm{P}<0.05$ (Student's $t$-test).

were observed in almost all rats. Nephroblastomas were noted in two female rats of group 4.

Yields of urinary bladder lesions are summarized in Table 4. Carcinomas were observed limited to rats given both BBN and Na-AsA (groups 1 and 4). The incidence and number were significantly higher in group 1 than in group 2 . Papillomas and PN hyperplasia in groups 1 and 4 were more frequent than in the BBN alone groups (groups 2 and 5) or the Na-AsA alone groups (groups 3 and 6). A statistical significant difference was found for the number of PN hyperplasia between groups 1 and 2 . The incidence of simple hyperplasia also showed a tendency similar to the case with papilloma or PN hyperplasia.

No tumor was observed in the ureters in all groups.

\section{Experiment 2}

Brdu-labeling index: BrdU-labeling indices for the urinary epithelium of the renal pelvis and urinary bladder are shown in Table 5. Values were increased significantly in female rats given $\mathrm{Na}$-AsA but not in males, for which the standard deviation was large. The trends for body weight, intake, and urinary analysis data with $\mathrm{Na}-\mathrm{As} \mathrm{A}$ 
Table 6. Urinary Concentration of BCPN in Experiment 3

\begin{tabular}{cccc}
\hline $\begin{array}{l}\text { No. of animals } \\
\text { examined }\end{array}$ & Body weight $(\mathrm{g})^{\mathrm{a}}$ & \multicolumn{2}{c}{$\operatorname{BCPN}(\mu \mathrm{g} / \mathrm{mL})^{\mathrm{a}}$} \\
\cline { 3 - 4 } & $350 \pm 19$ & $82 \pm 22^{\mathrm{b}}$ & $145 \pm 16$ \\
\hline
\end{tabular}

a: Mean \pm SD. b: Significantly different from the concentration in urinary bladder at $\mathrm{P}<0.01$ (Student's $t$-test).

administration were similar to those in Experiment 1.

\section{Experiment 3}

Detection of BCPN in the urine: Data for the BCPN concentration in the urine samples from the renal pelvis and urinary bladder in the same animals are shown in Table 6. The value for the renal pelvis was significantly lower than that for the urinary bladder.

\section{Discussion}

In the present study, promoting effects of $\mathrm{Na}$-AsA were found on lesion development in the urothelium of renal pelvis in male and female SD/cShi rats. In both sexes of rats, BrdU-labeling indices for the urothelial epithelial cells of renal pelvis were increased as well as for the urinary bladder administered $\mathrm{Na}-\mathrm{AsA}$ alone.

In the two-stage carcinogenesis, the urinary bladder epithelium in SD/cShi rats appears to be more sensitive to the promoting effects of $\mathrm{Na}-\mathrm{AsA}$ than the renal pelvic epithelium. Moreover, there was a definite sex difference in the degree of promotion in both the renal pelvis and the urinary bladder. These results did not reflect the data of BrdU-labeling index in the urothelium obtained from the short term administration of Na-AsA alone. Therefore, these differences may be mainly attributable to variation in the degree of initiation by $\mathrm{BBN}$, because rats receiving $\mathrm{BBN}$ alone exhibited a higher incidence and grade of proliferative lesions in the urinary bladder than in the kidney and in male than in female rats. Furthermore, the urinary concentration of a proximate carcinogen, BCPN, was approximately two times higher in the urinary bladder than in the renal pelvis. Similar results concerning the urinary concentration of BCPN were also obtained for SD/gShi rats which have normal kidneys (data not shown). The difference might be due to the difference in the period of retention of urine, because in the renal pelvis BCPN is continuously transferred into the urinary bladder and is diluted by fresh urine supplied by the kidney, while in the urinary bladder it is stored until urination occurs. Our previous experiment revealed hydronephrosis to be an important predisposing factor for the induction of renal pelvic carcinomas ${ }^{7}$. Urine stagnation in hydronephrosis may bring out greater exposure to urinary elements, including BCPN, for relatively longer time than in the normal kidney. Moreover, it might allow production of greater amounts of ultimate carcinogen from BCPN or BBN, because the urothelium has been reported to be able to metabolize $\mathrm{BCPN}$ or BBN, which are excreted into urine ${ }^{13-15}$. The difference in sensitivity to BBN between the renal pelvis and the urinary bladder might be attributable to the difference in the retained concentration of carcinogen.

Sex differences in initiation by $\mathrm{BBN}$ were here observed for both renal pelvis and urinary bladder carcinogenesis, in line with earlier findings when SD/cShi rats were administered $0.05 \% \mathrm{BBN}$ for 12 weeks and then untreated for 10 weeks $^{6}$. It has been reported that the incidence of urinary bladder cancers in animals induced by $\mathrm{BBN}$ is affected by hormonal status ${ }^{16-19}$. This may be due to effects on the metabolism of BBN to BCPN in the liver and kidney and the expression and turnover of metabolizing enzymes ${ }^{13,20-24}$. Thus, sex differences in the hepatic and renal metabolism of BBN might be involved in the higher sensitivity to $\mathrm{BBN}$ in male than female $\mathrm{SD} / \mathrm{cSh}$ rats.

In the long term experiment (Experiment 1), the incidence and grade of proliferative lesions induced by the administration of $\mathrm{Na}$-AsA alone were markedly higher in kidney and slightly higher in urinary bladder of male rats than female rats. This result was in accordance with the data of BrdU-labeling index in short term experiment (Experiment 2). However, the sex differential observed in the long term experiment did not reflect the short term experiment in which the BrdU-labeling index was increased to a greater extent in females. In the two-stage carcinogenesis experiment, the urinary concentration of ascorbic acid and sodium ion in female rats given $\mathrm{Na}-\mathrm{AsA}$ was lower than in male rats, while the $\mathrm{pH}$ of the urine did not markedly differ. In our previous two-stage urinary bladder carcinogenesis experiment, the urinary concentration of ascorbic acid in ODS rats, which lack L-ascorbic acid synthesizing ability, was significantly lower than WS/Shi rats, without differences in the concentration of sodium ions or $\mathrm{pH}$, but the incidence of urinary bladder carcinoma did not vary significantly between these strains of rats ${ }^{25}$. Various sodium salts of organic acids have the potential to promote the proliferation of epithelial cells in the second stage of urinary bladder carcinogenesis in the rat ${ }^{1}$. It was reported that the sodium ion concentration under conditions of equal increase of urinary $\mathrm{pH}$ affects the development of carcinomas in the urinary bladder ${ }^{1}$. Therefore, the difference of sodium ion concentration might have contributed to the sex differential in the proliferating effects of Na-AsA alone on the urothelium in long and short term experiments, although the cause of the sex differential in sodium ion concentration in the urine of rats is obscure.

Acknowledgements: The authors are gratefully indebted to Dr. Malcolm A. Moore at National Cancer Center for helpful comments and critical review of this manuscript. We would like to thank Ms. Motoko Hosono and Mr. Tadao Oohara at Aburahi Laboratories, Shionogi Research Laboratories, Shionogi \& Co., Ltd., for their technical assistance. 


\section{References}

1. Fukushima $\mathrm{S}$ and Murai T. Calculi, precipitates and microcrystallulia associated with irritation and cell proliferation as a mechanism of urinary bladder carcinogenesis in rats and mice. In: Species Differences in Thyroid, Kidney and Urinary Bladder Carcinogenesis, Capen CC, Dybing E, Rice JM, and Wilbourn JD (eds), IARC Scientific Publications, No. 147, 159-174, 1999.

2. Bach PH and Bridges JW. Chemically induced renal papillary necrosis and urothelial carcinoma. CRC Crt Rev Toxicol 1985; 15: 216-329.

3. Ceovic S, Plestina R, Miletic-Medved M, Stavljenic A, Mitar J, and Vukelic M. Epidemiological aspects of Balkan endemic nephropathy in a typical focus in Yugoslavia. IARC Sci Publ 1991; 115: 5-10.

4. Yang MH, Chen KK, Yen CC, Wang WS, Chang YH, Huang WJ, Fan FS, Chiou TJ, Liu JH, and Chen PM. Unusually high incidence of upper urinary tract urothelial carcinoma in Taiwan. Urology 2002; 59: 681-687.

5. Nakao H, Seko S, Sugimori Y, Makino S, Mikazuki K, and Inoue T. Establishment of spontaneous hydronephrosis in Sprague-Dawley rats. Exp Anim 1972; 21: 146-147 (in Japanese).

6. Mori S, Hosono M, Machino S, Nakai S, Makino S, Nakao H, Takeuchi Y, Takeda R, Murai T, and Fukushima S. Induction of the renal pelvic and ureteral carcinomas by $\mathrm{N}$ butyl-N-(4-hydroxybutyl)nitrosamine in $\mathrm{SD} / \mathrm{cSh}$ rats with spontaneous hydronephrosis. Toxicol Pathol 1994; 22: 373379.

7. Murai T, Mori S, Machino S, Hosono M, Takeuchi Y, Ohara T, Makino S, Takeda R, Hayashi Y, Iwata H, Yamamoto S, Ito $\mathrm{H}$, and Fukushima $\mathrm{S}$. Induction of renal pelvic carcinoma by phenacetin in hydronephrosis-bearing rats of the SD/cShi strain. Cancer Res 1993; 53: 4218-4223.

8. Institute of Laboratory Animal Resources, Commission on Life Sciences, National Research Council. Guide for the care and use of laboratory animals. Washington, DC: National Academy Press, 1996.

9. Okada M, Suzuki E, and Iiyoshi M. Syntheses of N-alkyl-N( $\omega$-carboxypropyl)nitrosamines related to $N$-butyl- $N$-(3carboxypropyl)nitrosamine, principal uriary metabolite of a potent bladder carcinogen $N$-butyl- $N$-(4hydroxybutyl)nitrosamine. Chem Pharm Bull 1978; 26: 3909-3913.

10. Ozaki K, Sukata T, Yamamoto S, Uwagawa S, Seki T, Kawasaki H, Yoshitake A, Wanibuchi H, Koide A, Mori Y, and Fukushima S. High sensitivity of $p 53(+/-)$ knockout mice in $N$-butyl- $N$-(4-hydroxybutyl)nitrosamine urinary bladder carcinogenesis and lack of frequent mutation in residual allele. Cancer Res 1998; 58: 3806-3811.

11. Fukushima S, Murasaki G, Hirose M, Nakanishi K, Hasegawa R, and Ito N. Histopathological analysis of preneoplastic changes during $\mathrm{N}$-butyl- $\mathrm{N}$-(4hydroxybutyl)nitrosamine-induced urinary bladder carcinogenesis in rats. Acta Pathol Jpn 1982; 32: 243-250.

12. Morstyn G, Hsu S-M, Kinsella T, Gratzner H, Russo A, and Mitchell JB. Bromodeoxyurinide in tumors and chromosomes detected with a monoclonal antibody. J Clin Invest 1983; 72: 1844-1850.

13. Airoldi L, Magagnotti C, De Gregorio G, Moret M, and Fanelli R. In vitro metabolism of bladder carcinogenic nitrosamines by rat liver and urothelial cells. Chem Biol Interact 1992; 82: 231-240.

14. Bonfanti M, Magagnotti C, Bonati M, Fanelli R, and Airoldi L. Pharmacokinetic profile and metabolism of Nnitrosobutyl-N-(4-hydroxybutyl)amine in rats. Cancer Res 1988; 48: 3666-3669.

15. Airoldi L, Magagnotti C, Bonfanti M, Moret M, and Fanelli R. N-nitrosobutyl(4-hydroxybutyl)amine $\alpha$-hydroxylation by rat liver and urothelial cell homogenates. IARC Sci Publ 1991; 105: 343-345.

16. Bertram JS and Craig AW. Specific induction of bladder cancer in mice by butyl-(4-hydroxybutyl)nitrosamine and the effects of hormonal modification on the sex differences in response. Eur J Cancer 1972; 8: 587-594.

17. Kono N, Sasaki N, Umetsu R, and Otani T. An attempt of hormonal control of rats urinary bladder tumors chemically induced. Kobe J Med Sci 1973; 19: 151-160.

18. Kono N, Tanahashi T, Suzawa N, and Azuma C. Effects of sex hormones on oncogenesis in rat urinary bladder by $N$ butyl- $N$-(4-hydroxybutyl)nitrosamine. Int J Clin Pharmacol 1977; 15: 101-105.

19. Okajima E, Hiramatsu T, Iriya K, Ijuin M, Matsushima S, and Yamada K. Effects of sex hormones on development of urinary bladder tumours in rats induced by N-butyl-N-(4hydroxybutyl)nitrosamine. Urol Res 1975; 3: 73-79.

20. Einarsson K, Gustafsson J-A, and Stenberg A. Neonatal imprinting of liver microsomal hydroxylation and reduction of steroids. J Biol Chem 1973; 248: 4987-4997.

21. Levin W, Ryan D, Kuntzman R, and Conney AH. Neonatal imprinting and the turnover of microsomal cytochrome P450 in rat liver. Mol Pharmacol 1975; 11: 190-200.

22. Shimada M, Murayama N, Yamazoe Y, Kamataki T, and Kato R. Further studies on the persistence of neonatal androgen imprinting on sex-specific cytochrome P-450, testosterone and drug oxidations. Jpn J Pharmacol 1987; 45: 467-478.

23. Imaoka $\mathrm{S}$, Yoneda $\mathrm{Y}$, Sugimoto $\mathrm{T}$, Ikemoto $\mathrm{S}$, Hiroi $\mathrm{T}$, Yamamoto K, Nakatani T, and Funae Y. Androgen regulation of CYP4B1 responsible for mutagenic activation of bladder carcinogens in the rat bladder: detection of CYP4B1 mRNA by competitive reverse transcriptionpolymerase chain reaction. Cancer Lett 2001; 166: 119-123.

24. Mori Y, Koide A, Fuwa K, Wanibuchi H, and Fukushima S. Lack of change in the levels of liver and kidney cytochrome $\mathrm{P}-450$ isozymes in $\mathrm{p} 53+/-$ knockout mice treated with $\mathrm{N}$ butyl-N-(4-hydroxybutyl)nitrosamine. Mutagenesis 2001; 16: 377-383.

25. Murai $\mathrm{T}$, Mori S, Hosono M, Takashima A, Machino S, Oohara T, Yamashita H, Makino S, Matsuda T, Wanibuchi $\mathrm{H}$, and Fukushima S. Strain differences in sensitivity to the promoting effect of sodium L-ascorbate in a two-stage rat urinary bladder carcinogenesis model. Jpn J Cancer Res 1997; 88: 245-253. 